Research Paper:

\title{
Prevalence of Substance Abuse Among High School Students in Hamedan, Iran in 2015
}

\author{
Azar Pirdehghan ${ }^{1}$, Sahar Mahmoodi ${ }^{2}$, Mohammad Ali Seifrabie ${ }^{1}$, Mohammad Haghighi ${ }^{*}$ ( \\ 1. Department of Community and Preventive Medicine, School of Medicine, Hamadan University of Medical Sciences, Hamadan, Iran. \\ 2. Research Center for Behavioral Disorders and Substances Abuse, Hamadan University of Medical Sciences, Hamadan, Iran.
}

$\begin{gathered}\text { Use your device to scan } \\ \text { and read the article online }\end{gathered}$
Hamedan, Iran in 2015. Avicenna J of Neuropsychophysiology. 2019; 6(2):67-74. http://dx.doi.org/10.32598/ajnpp.4.3.295
d. http://dx.doi.org/10.32598/ajnpp.4.3.295

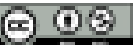

Article info:

Received: 10 Dec 2018

Accepted: 12Mar 2019

Available Online: 01 May 2019

Keywords:

Prevalence, Students,

Substance abuse

\section{ABSTRACT}

Background: Substance abuse is one of the main health challenges that lead to addiction and physical, psychological, and social issues. It can also eliminate the foundation of family and community.

Objectives: The present study aimed at determining the frequency of experience of at least once abuse of addictive drugs in high school students in Hamedan, Iran.

Materials and Methods: The present cross-sectional study was carried out in 2015 in high schools of Hamedan City. A self-report questionnaire was used to identify the number of cigarette smokers and other addictive substances abusers. The data were analyzed, using SPSS V. 14.

Results: Out of 800 distributed questionnaires, 29 questionnaires were incomplete. In total, 18\% of the students had abused addictive substances at least once. The most common substances were hookah, cigarette, and alcohol. Independent risk factors for substance abuse experience included male gender, non-governmental and vocational schools, mathematics major, history of the educational failure, an average of less than 17.00 GPA, unemployment of a student's father, and student's employment other than education.

Conclusion: The prevalence of hashish (cannabis) abuse and anabolic-androgenic steroids is high in Iran and codeine is the most commonly used substance in the non-prescribed groups.

\section{Introduction}

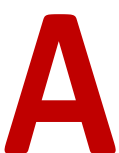

busing drugs such as alcohol, narcotics, analgesics, and other substances is becoming an important health problem in the world [1]. Unfortunately, drug abuse, especially opium use, is prevalent in Iran despite law and religion prohibition issues and the fact that it is not culturally acceptable among Iranian families [2]. Adolescence is a particularly vulnerable period for the initiation of drug use. Cigarette smoking, which is usually referred to as a gate to drug use, is prevalent in Iran. According to differ-

* Corresponding Author:

Mohammad Haghighi, PhD.

Address: Research Center for Behavioral Disorders and Substances Abuse, Hamadan University of Medical Sciences, Hamadan, Iran.

Tel: +98 (81) 38271066

E-mail: haghighi@umsha.ac.ir 
ent studies, its prevalence increased from $12.6 \%$ in 2000 to $14.3 \%$ in $2004[3,4]$.

Usually, the first experiences of smoking occur in adolescence and most adolescent smokers continue smoking to adulthood. In spite of the recent decline in the prevalence of smoking among the youth in developed countries, the problem has become more prevalent in many developing countries [5]. Hookah smoking is another problem, which is frequently used by adolescents and teenagers in Iran. Unlike so many drugs, which are not accepted in Iranian families, regarding hookah smoking, the families and the society in Iran are more permissive [6]. According to the few studies on social correlates of hookah smoking, the smokers consider it a pleasurable social hobby that promotes a sense of togetherness. They view it as a relatively harmless leisure time activity $[7,8]$. The results of a study in university students in Isfahan, Iran, revealed that cigarette and hookah smoking is significantly associated with having smoking friends.

According to this study, $9.5 \%$ of the students were cigarette smokers and $19.5 \%$ were hookah smokers [9]. As there is no nationwide survey among adolescents in Iran on alcohol and other drugs, the prevalence of drug use in this group remains unclear in Iran. In a rapid situational assessment in Iran (2007), it was shown that $18.9 \%$ of drug abusers were younger than 24 years [10]. Another study has shown that, for many adolescents in Iran, the age of drug use onset is under 18, and many of them used drugs for the first time in schools or their friends' homes [11].

In a systematic review in 2010 about substance abuse among Iranian high school students, drug abuse was a frequent problem among Iranian high school students. This study revealed that the early onset of tobacco smoking with daily use rates between $4.4 \%$ and $12.8 \%$ in high school students. Also, alcohol was the most frequently abused substance with a lifetime rate of at least $9.9 \%$. Lifetime rates of opiate use were mostly between 1.2 and $8.6 \%$ in different parts of the country [10]

Relationship between substance abuse and addictive behaviors in adolescents with other deviants, on the one hand, and its inextricable link with problems such as mental disorders, home escape, aggression, violence in social behaviors, theft and larceny, studying and attempting suicide and prostitution, on the other hand, point to the importance of re-thinking and meditating on this issue.
Few studies have investigated drug use in students in Iran. So, this study aimed at evaluating drug use in high school students in Hamedan, Iran.

\section{Materials and Methods}

The sample size of the present cross-sectional study was calculated 800 individuals out of 6830 high school students in Hamadan based on similar studies and considering $\mathrm{P}=0.18, \mathrm{~d}=0.03, \mathrm{z}=1.96$, and design effect $=2$. The sampling was done in a two-stage cluster manner, through which the schools were considered clusters and the schools were selected based on the population. Multistage cluster and random sampling methods were used for sampling. First, based on the population of each educational area, the number of samples was divided between 2 regions. Then, in each area, 5 boys and 5 girls high schools were randomly selected. According to the ratio of the field of study, 1 or 2 classes of each school were randomly selected. Finally, out of 6830 high school students studying in 72 educational units of Hamedan, 800 students were randomly selected.

The inclusion criteria included studying in the high schools of Hamadan in 2015. The exclusion criteria included the lack of willingness and written consent of participating in the study. We used the United Nations Office on Drugs and Crime substance abuse questionnaire, which was considered to be used in schools and its validity had already been confirmed [12].

The study protocol was approved by the Ethics Committee of Hamadan University of Medical Sciences. After receiving an allowance from the education and training organization and school officials, followed by introducing themselves and the research goals to students and accenting on the confidentiality of information, the executives distributed the questionnaires among the students. The executives asked the participants to put the questionnaire inside the box in the class after its nameless fulfillment so that the confidentiality of information would be ensured.

The questionnaire includes two parts; demographic information and questions about the use of 40 different substances or drugs, in which "never use" was coded as 0 , "having at least one experience" as 1 , and "more than once" as 2. Other information about the age of the first experience and encouragers for substance use were also asked. Finally, the data were analyzed by the Logistic Regression Model and Chi-Square or Fisher exact test, using SPSS v. 14. P<0.05 was considered statistically significant. 
In this study, Mohammadkhani's drug use questionnaire was used and supervised by social medicine specialists. The drug use questionnaire (in Persian) is a researcher-made tool based on the United Nations Office on Drugs and Drug Addiction to determine the rate of smoking, alcohol, and other types of materials in domestic and foreign research. It has good psychometric properties and its reliability coefficient is $87 \%$ [11].

\section{Results}

Out of the 800 distributed questionnaires among the students, 29 were not completed and the response rate to the questionnaire was $96.4 \%$. Of the 771 studied students, 367 (47.6\%) were female and 404 (52.4\%) were male. The Mean \pm SD age of the students was $17.36 \pm 1.96$ years. Around $80 \%$ of the students studied in governmental schools and $22 \%$ of them had jobs while studying in high school. Table 1 presents the demographic information of the students.

The most commonly used substances were hookah (24.2\%) and cigarette (15.3\%). Lighter gas, ecstasy, Ritalin $^{\circledR}$, phenobarbital, lysergic acid diethylamide (LSD), and heroin were the least frequent. Among the unsubscribed substances, codeine $(n=51 ; 6.6 \%)$ was the most frequent (Table 2).

Concerning alcohol consumption, as presented in Table 3, non-alcohol use was significantly higher in girls than boys ( $98.3 \%$ vs. $77.4 \%$ ). Alcohol consumption more than once was significantly higher in boys than girls (15.1\% vs. 1.1\%). There was no significant difference between the two sexes in alcohol consumption once.

Compared to girls, boys showed an increased prevalence of addictive substance abuse once or more. The observed differences were statistically significant, with hookah and cigarette showing the highest prevalence in boys (Table 3 ). In addictive substances, girls were always less likely to use than boys with a significant difference except for hashish.

The history of educational failure, which was also similar to less than 17 years, was associated with a significant increase in the consumption of more addictive substances among the students; however, this association was not observed in the abuse of medication without a physician's prescription (Table 4).

One of the factors that contributed to the higher risk of consuming addictive substance was the employment of students in jobs while studying in high school, which increased the risk of drug abuse. Meanwhile, cigarette and hookah were the most consumed substances among such students (Table 5).

\section{Discussion}

The present study aimed at identifying the prevalence of substance addiction and its association among high school students in Hamedan. In total, $47.22 \%$ of the students ( $18.4 \%$ of boys and $4 \%$ of girls) abused addictive substances at least once. The most commonly used addictive substances among all the students were hookah, cigarette, alcohol, codeine, hashish, anabolicandrogenic steroids (AAS), opium, morphine, methadone, diphenoxylate, crystal, heroin, LSD, Ritalin ${ }^{\circledR}$, and lighter gas. Furthermore, the most common substances in girls were hookah, cigarette, alcohol, and codeine. In boys, the most common addictive substances were hookah, cigarette, hashish, alcohol, and bodybuilding drugs. In most studies, the most commonly used substances were hookah, cigarette, alcohol, opium, bodybuilding drugs, ecstasy, hashish, heroin, cocaine, crystal, crack cocaine, morphine, and LSD, which is in line with the findings of the present study compared to alcohol. The prevalence of substance abuse is at least one of the addictive drugs mentioned in the present study. In students of this study, cocaine and phencyclidine abuse were not reported, and in other studies, the abuse was reported from $0.2 \%$ to $0.49 \%$. In addition, in this study, hashish was ranked fifth, preceded by the bodybuilding drugs and opium [13-16].

Experience of at least once abuse of addictive substance, experience among the girls, and experience among the boys in this study were less than those of the same studies; however, this rate was more than the rates mentioned in studies by Pirdehghan et al. [17] in Yazd, Agahi in Isfahan, and Mohammadpoor in Tabriz. The above-mentioned studies explained the differences in addictive substances studied in particular studies, including or not including smoking cigarettes or hookah. Therefore, it seems that the homogeneity of epidemiological techniques helps to understand the experience of abuse more accurately.

Generally, $14 \%$ of the cigarette smokers and $40 \%$ of the hookah smokers are considered abusing at least once because of the cultural and religious backgrounds, the explicit and unconditional prohibition of the use of other substances, and the teaching of such denial since childhood. But, the absence of religious, social, and cultural prohibitions, as a decisive factor in cigarette and hookah smoking, can justify the high prevalence in such 
Table 1. Basic characteristics of the participants

\begin{tabular}{|c|c|c|c|}
\hline \multicolumn{2}{|c|}{ Variables } & \multirow{2}{*}{$\begin{array}{l}\text { No. } \\
404\end{array}$} & \multirow{2}{*}{$\begin{array}{c}\text { \% } \\
52.4\end{array}$} \\
\hline & Male & & \\
\hline Sex & Female & 367 & 47.6 \\
\hline Age (y) & Mean \pm SD & & \\
\hline \multirow{2}{*}{ School } & Governmental & 610 & 79.1 \\
\hline & Private & 161 & 20.9 \\
\hline \multirow{4}{*}{ Father's education } & Illiterate & 52 & 6.9 \\
\hline & Under high school graduates & 214 & 28.2 \\
\hline & High school graduates & 285 & 37.6 \\
\hline & Academic & 207 & 27.3 \\
\hline \multirow{4}{*}{ Mother's education } & Illiterate & 66 & 8.8 \\
\hline & Under high school graduates & 248 & 32.3 \\
\hline & High school graduates & 302 & 40.1 \\
\hline & Academic & 53 & 18.8 \\
\hline \multirow{3}{*}{ Father's occupation } & Unemployed & 22 & 2.9 \\
\hline & Self-employed & 444 & 58.9 \\
\hline & Employed & 288 & 38.2 \\
\hline \multirow{3}{*}{ Mother's occupation } & Housekeeper & 581 & 76.4 \\
\hline & Employed & 108 & 14.2 \\
\hline & Other & 51 & 7.0 \\
\hline \multirow{2}{*}{ Parent living together } & Yes & 691 & 89.6 \\
\hline & No & 80 & 10.4 \\
\hline \multirow{2}{*}{ Living with parents } & Yes & 691 & 89.4 \\
\hline & Other & 82 & 10.6 \\
\hline \multirow{2}{*}{ Parent's death (either one or both) } & Yes & 25 & 3.2 \\
\hline & No & 746 & 96.8 \\
\hline \multirow{2}{*}{ Educational failure } & Yes & 112 & 6.0 \\
\hline & No & 659 & 94.0 \\
\hline \multirow{3}{*}{ Educational course } & Mathematical & 118 & 25.9 \\
\hline & Empirical sciences & 224 & 49.3 \\
\hline & Human sciences & 113 & 24.8 \\
\hline \multirow{2}{*}{$\begin{array}{c}\text { Occupation of the student while } \\
\text { studying }\end{array}$} & Yes & 155 & 22.1 \\
\hline & No & 546 & 77.9 \\
\hline
\end{tabular}


Table 2. Frequency of addiction abuse among students

\begin{tabular}{|c|c|c|c|}
\hline \multirow{2}{*}{ Substance } & \multicolumn{3}{|c|}{ No. (\%) } \\
\hline & Once Abuse & More Than Once & Total \\
\hline Cigarettes & $22(5.7)$ & $38(9.6)$ & $60(15.3)$ \\
\hline Hookah & $33(8.2)$ & $65(16.2)$ & $98(24.2)$ \\
\hline Alcohol & $10(2.5)$ & $25(5.7)$ & $35(8.2)$ \\
\hline Opium & $2(0.91)$ & $5(0.65)$ & $7(0.91)$ \\
\hline Hashish & $2(0.26)$ & $10(1.3)$ & $12(1.56)$ \\
\hline Ecstasy & $1(0.13)$ & $1(0.13)$ & $2(0.26)$ \\
\hline Methamphetamine & $0(0)$ & $2(0.26)$ & $2(0.26)$ \\
\hline LSD & $2(0.26)$ & $2(0.26)$ & $2(0.26)$ \\
\hline Lighter gas & $0(0)$ & $1(0.13)$ & $1(0.13)$ \\
\hline Codeine & $18(2.33)$ & $33(4.71)$ & $51(6.61)$ \\
\hline Methadone & $1(0.13)$ & $2(0.26)$ & $3(0.39)$ \\
\hline Morphine & $4(0.52)$ & $0(0)$ & $4(0.52)$ \\
\hline Ritalin $^{\circledast}$ & $1(0.13)$ & $0(0)$ & $1(0.13)$ \\
\hline Difenoxylate & $2(0.26)$ & $1(0.13)$ & $3(0.39)$ \\
\hline Phenobarbital & $0(0)$ & $1(0.13)$ & $1(0.13)$ \\
\hline AAS & $7(0.91)$ & $10(1.3)$ & $17(2.20)$ \\
\hline Heroin & $0(0)$ & $2(0.26)$ & $2(0.26)$ \\
\hline Cocaine & $0(0)$ & $3(0.39)$ & $3(0.39)$ \\
\hline Total & 105 (22.47) & 201 (37.9) & $306(60.37)$ \\
\hline
\end{tabular}

AJNPP

studies. Furthermore, the freedom to smoke and the risk of using narcotics, especially hookah, is high, which is because of the lower expectations of hookah risks in the mind of the abusers [18].

According to the results of this study, the experience of cigarette smoking at least once, as well as hookah as an independent risk factor, can multiple the chance of experiencing other substances, especially alcohol and opioids. Hence, the importance of carefully considering, problem-solving, and preventing the prevalence of cigarette and hookah smoking among students is of high importance.

In the present study, $7(0.9 \%)$ students at least once and $10(1.3 \%)$ more than once experienced the abuse of bodybuilding drugs, which was a higher rate compared with other studies; however, it was with a lower prevalence compared to the studies of Pirdehghan et al. in Yazd [17] and Ziaoddini et al. in Kerman.

In the current study, one of the independent risk factors and also the predictors of the addictive substance abuse experience, which is 17 times more likely, was gender. It was common among the boys. Also, the experience of at least once and more than once was significantly dominant in males than in females. This principle is similar to the result of numerous studies in this field [10,17-19]. The possible causes of the gender difference in the prevalence of narcotic drugs in Iran is the availability of more facilities and family freedom of children mentioned in such families. The possibility of 
Table 3. Prevalence of addictive substance abuse based on gender

\begin{tabular}{|c|c|c|c|c|c|c|c|c|c|}
\hline \multicolumn{4}{|c|}{ Once } & \multicolumn{3}{|c|}{ More Than Once } & \multicolumn{3}{|c|}{ Never } \\
\hline \multirow{2}{*}{ Substance } & \multicolumn{2}{|c|}{ No. (\%) } & \multirow{2}{*}{$\mathbf{P}$} & \multicolumn{2}{|c|}{ No. (\%) } & \multirow{2}{*}{$\mathbf{P}$} & \multicolumn{2}{|c|}{ No. (\%) } & \multirow{2}{*}{$\mathbf{P}$} \\
\hline & Male & Female & & Male & Female & & Male & Female & \\
\hline Cigarettes & $14(3.5)$ & $8(2.2)$ & 0.201 & $33(8.2)$ & $5(1.4)$ & 0.001 & 357 (88.4) & 354 (96.3) & 0.001 \\
\hline Hookah & 31 (7.7) & $2(0.5)$ & $<0.001$ & 61 (15.1) & $4(1.1)$ & 0.001 & $312(77.2)$ & 361 (98.3) & $<0.001$ \\
\hline Alcohol & $8(2.0)$ & $2(0.5)$ & 0.058 & $22(5.4)$ & $3(0.3)$ & 0.001 & 374 (92.5) & 362 (98.6) & $<0.001$ \\
\hline Hashish & $2(0.5)$ & - & - & $10(2.5)$ & $0(0)$ & 0.001 & 394 (97.52) & 357 (97.27) & 0.828 \\
\hline Codeine & $2(0.5)$ & 0 & - & $23(5.7)$ & $9(2.5)$ & 0.018 & 379 (93.81) & 358 (97.55) & 0.021 \\
\hline Others* & $2(0.5)$ & 0 & - & 41 (10.1) & $7(1.9)$ & 0.018 & 361 (89.36) & 360 (97.09) & $<0.001$ \\
\hline
\end{tabular}

* Opium, Crystal, Ecstasy, Diphenoxylate, AAS, Phenobarbital, Ritalin, Morphine, Methadone

Table 4. Substance abuse based on previous educational failure in their recent years

\begin{tabular}{|c|c|c|c|c|c|}
\hline \multirow{3}{*}{ Substance } & \multirow{3}{*}{ Once } & \multirow{3}{*}{ Total No. (\%) } & \multicolumn{2}{|c|}{ No. (\%) } & \multirow{3}{*}{$\mathbf{P}$} \\
\hline & & & \multicolumn{2}{|c|}{ History of Educational Failure } & \\
\hline & & & Yes & No & \\
\hline \multirow{3}{*}{ Cigarette } & Yes & 38 (4.9) & $14(12.4)$ & $24(3.6)$ & \multirow{3}{*}{0.001} \\
\hline & & & & & \\
\hline & No & 633 (95.1) & $99(87.6)$ & $634(96.4)$ & \\
\hline \multirow{3}{*}{ Hookah } & Yes & $65(8.4)$ & $16(14.2)$ & $49(7.4)$ & \multirow{3}{*}{0.019} \\
\hline & & & & & \\
\hline & No & 7.8 (91.6) & $97(85.8)$ & 609 (92.6) & \\
\hline \multirow{3}{*}{ Alcohol } & Yes & $34(4.4)$ & $14(12.4)$ & $20(3.0)$ & \multirow{3}{*}{0.001} \\
\hline & & & & & \\
\hline & No & $737(95.6)$ & $99(87.6)$ & $638(0.97)$ & \\
\hline \multirow{3}{*}{ Hashish } & Yes & $10(1.3)$ & $4(305)$ & $6(0.9)$ & \multirow{3}{*}{0.037} \\
\hline & & & & & \\
\hline & No & $761(98.7)$ & 109 (96.5) & $652(99.1)$ & \\
\hline \multirow{3}{*}{ Codeine } & Yes & $32(4.8)$ & $4(3.5)$ & $28(4.3)$ & \multirow{3}{*}{0.199} \\
\hline & & & & & \\
\hline & No & $739(95.8)$ & 109 (96.5) & $630(95.7)$ & \\
\hline \multirow{3}{*}{ Other substance* } & Yes & $48(6.2)$ & $6(5.3)$ & $42(5.3)$ & \multirow{3}{*}{0.428} \\
\hline & & & & & \\
\hline & No & 723 (93.8) & 107 (94.7) & 616 (93.6) & \\
\hline
\end{tabular}

* Opium, Crystal, Ecstasy, Diphenoxylate, Bodybuilding drugs, Phenobarbital, Ritalin, Morphine, and Methadone

earning money and, on the other hand, more accurate control of families on the type of their girls' relationship is another possible factor for such differences [20]. Besides, girls' attitude toward substance was significantly worse than the boys and they consider it a serious issue that can indicate differences in cultural approaches toward gender.
In recent years, there has been an increase in leniency in the tendency of girls to consume the addictive substance, and the gap between the genders has decreased in substance abuse [21]. Moreover, in studies conducted in European countries, in particular in Great Britain and France, the relative frequency of cigarette abuse in both genders is close together and even girls have a false belief in cigarette usefulness in body fitness 
Table 5. Type and amount of substance use among students based on employment other than education

\begin{tabular}{|c|c|c|c|c|c|}
\hline \multirow{3}{*}{ Substance } & \multirow{3}{*}{$\begin{array}{c}\text { Abuse More than One } \\
\text { Time }\end{array}$} & \multirow{3}{*}{ Total No. (\%) } & \multicolumn{2}{|c|}{ No. (\%) } & \multirow{3}{*}{$\mathbf{P}$} \\
\hline & & & \multicolumn{2}{|c|}{ Part-time Employment While Studying } & \\
\hline & & & Yes & No & \\
\hline \multirow{3}{*}{ Cigarette } & Yes & $38(5.0)$ & $14(9.0)$ & $24(3.9)$ & \multirow{3}{*}{0.033} \\
\hline & & & & & \\
\hline & No & $727(95.0)$ & $141(91.0)$ & 585 (96.1) & \\
\hline \multirow{3}{*}{ Hookah } & Yes & $64(8.4)$ & 25 (16.1) & $39(6.4)$ & \multirow{3}{*}{0.000} \\
\hline & & & & & \\
\hline & No & 701 (91.6) & 130 (83.9) & 571 (93.6) & \\
\hline \multirow{3}{*}{ Alcohol } & Yes & $25(3.3)$ & $8(5.2)$ & $17(2.9)$ & \multirow{3}{*}{0.068} \\
\hline & & & & & \\
\hline & No & 740 (96.7) & $147(96.7)$ & 593 (97.1) & \\
\hline \multirow{3}{*}{ Hashish } & Yes & $10(1.3)$ & $2(1.3)$ & $8(1.3)$ & \multirow{3}{*}{0.304} \\
\hline & & & & & \\
\hline & No & 755 (98.7) & $154(98.7)$ & $601(98.7)$ & \\
\hline \multirow{3}{*}{ Codeine } & Yes & 32 (95.8) & $9(5.8)$ & $23(3.8)$ & \multirow{3}{*}{0.518} \\
\hline & & & & & \\
\hline & No & $733(95.8)$ & $147(94.2)$ & $586(98.2)$ & \\
\hline \multirow{2}{*}{$\begin{array}{l}\text { Other sub- } \\
\text { stance* }\end{array}$} & Yes & $48(6.3)$ & $14(9)$ & $34(5.6)$ & \multirow{2}{*}{$\begin{array}{l}0.043 \\
\text { AJNPP }\end{array}$} \\
\hline & No & $717(93.7)$ & $142(91)$ & $575(94.4)$ & \\
\hline
\end{tabular}

* Opium, Crystal, Ecstasy, Diphenoxylate, Bodybuilding drugs, Phenobarbital, Ritalin ${ }^{\circledR}$, Morphine, and Methadone

than boys, which makes this difference $[22,23]$. Also, this study does not indicate any statistically significant difference in the tendency of substance abuse in both genders.

In this research, the Grade Point Average (GPA) of the previous year and the history of resubmission or rejection are among the independent factors and predictors of risk of substance abuse. Thus, abusing cigarettes, hookah, alcohol, and hashish were significantly higher in students with an average GPA of less than 17 and a history of educational failure was significantly higher than students with an average GPA of +17 or no history of educational failure.

One of the possitive points of the present study is the relatively large number of materials compared with previous studies and further consideration of more confusing variables. However, among the limitations of this study, the actual prevalence of abuse in some certain substances (substances except cigarettes, hookah, alcohol, addictive drugs, and bodybuilding) is likely to be higher in students. The cultural conditions of society, the perceived crime of substance abuse, and the possi- bility of disturbing the course of lifestyle and education justify this affair.

Considering the high prevalence of abuse in adolescents, life skills and preventive ways to avoid substance abuse in primary and secondary schools must be developed. It increases the awareness of students and their families and reduces the prevalence and complications of substance abuse. The use of hashish and AAS are at a high level compared to studies in other parts of Iran and are on the top of the category of drug administration without physicians' prescription. Target groups for changing attitudinal programs to prevent potential addictive substance abuse include male students, senior ages, the family of the last child, those studying in non-profit or vocational schools or studying in a mathematics course, those with school resubmission (re-examination) or educational failure, and those with unemployed father. 


\section{Ethical Considerations}

\section{Compliance with ethical guidelines}

All ethical principles were considered in this article. The participants were informed about the purpose of the research and its implementation stages; they were also assured about the confidentiality of their information; Moreover, They were allowed to leave the study whenever they wish, and if desired, the results of the research would be available to them.

\section{Funding}

This research did not receive any specific grant from funding agencies in the public, commercial, or not-forprofit sectors.

\section{Authors' contributions}

All authors contributed equally in preparing all parts of the research.

\section{Conflict of interest}

The authors declared no conflict of interest.

\section{References}

[1] World Health Organization. Management of substance abuse Facts and figures. [Internet]. 2018. [Cited Jun 19]. Available from: http:// www.who.int/substance_abuse/facts/en/.

[2] Mohammadpoorasl A, Fakhari A, Rostami F, Vahidi R. Predicting the initiation of substance abuse in Iranian adolescents. Addict Behav. 2007; 32(12):3153-9. [DOI:10.1016/j.addbeh.2007.07.014] [PMID]

[3] Hessami Z, Masjedi MR, Ghahremani R, Kazempour M, Emami H. Evaluation of the prevalence of waterpipe tobacco smoking and its related factors in Tehran, Islamic Republic of Iran. East Mediterr Health J. 2017; 23(2):94-9. [DOI:10.26719/2017.23.2.94] [PMID]

[4] Sarraf-Zadegan N, Boshtam M, Shahrokhi S, Naderi GA, Asgary S, Shahparian $\mathrm{M}$, et al. Tobacco use among Iranian men, women and adolescents. Eur J Public Health. 2004; 14(1):76-8. [DOI:10.1093/ eurpub/14.1.76] [PMID]

[5] Ghasemian A, Rezaei N, Saeedi Moghaddam S, Mansouri A, Parsaeian $M$, Delavari A, et al. Tobacco smoking status and the contribution to burden of diseases in Iran, 1990-2010: Findings from the Global Burden of Disease Study 2010. Arch Iran Med. 2015; 18(8):493-501. [PMID]

[6] Maziak W, Eissenberg T, Rastam S, Hammal F, Asfar T, Bachir ME, et al. Beliefs and attitudes related to narghile (waterpipe) smoking among university students in Syria. Ann Epidemiol. 2004; 14(9):64654. [DOI:10.1016/j.annepidem.2003.11.003] [PMID]
[7] Chidiac A, Tamim H, Kanso M, Tfayli A. Smoking among Lebanese medical students: Prevalence and attitudes. Ann Thorac Med. 2016; 11(3):183-90. [DOI:10.4103/1817-1737.185757] [PMID] [PMCID]

[8] Jawad M, Charide R, Waziry R, Darzi A, Ballout RA, Akl EA. The prevalence and trends of waterpipe tobacco smoking: A systematic review. PLOS ONE. 2018; 13(2):e0192191. [DOI:10.1371/journal. pone.0192191] [PMID] [PMCID]

[9] Roohafza H, Sadeghi M, Shahnam M, Shokouh P, Teimori S, Amirpour $A$, et al. Social norms of cigarette and hookah smokers in Iranian universities. ARYA Atheroscler. 2013; 9(1):45-50.

[10] Momtazi S, Rawson R. Substance abuse among Iranian high school students. Curr Opin Psychiatry. 2010; 23(3):221-6. [DOI:10.1097/ YCO.0b013e328338630d] [PMID] [PMCID]

[11] Nakhaee N, Ziaaddini H, Karimzadeh A. Epidemiologic study on drug abuse among first and second grade high school students in Kerman. Addict Health. 2009; 1(1):31-6. [PMID] [PMCID]

[12] UNODC (United Nations Office on Drugs and Crime). World drug report 2010. Vienna: United Nations Publications; 2010.

[13] Ghaderi A, Motmaen M, Abdi I, Rasouli-Azad M. Gender differences in substance use patterns and disorders among an Iranian patient sample receiving methadone maintenance treatment. Elec tron Physician. 2017; 9(9):5354-62. [DOI:10.19082/5354] [PMID] [PMCID]

[14] Iranpour A, Jamshidi E, Nakhaee N, Haghdoost AA, Shojaeizadeh D, Eftekhar-Ardabili M, et al. Development and psychometric properties of risk and protective factors of substance use scale in Iran: An application of social development model. Addict Health. 2015 7(3-4):117-29. [PMID] [PMCID].

[15] Merghati-Khoei ES, Rezaei Z, Shojaei-Zadeh D, Azadi NA, Rimaz $S$, Bayat $A$, et al. Sexual risk behaviors and condom use barriers in Iranian men with substance use disorders. Addict Health. 2017 9(1):40-7. [PMID] [PMCID]

[16] Taghaddosinejad F, Arefi M, Fayaz AF, Tanhaeivash R. Determination of substance overdose in two Iranian centers: Comparison between opioids and non-opioids. J Forensic Leg Med. 2013; 20(3):155-7. [DOI:10.1016/j.jflm.2012.06.012] [PMID]

[17] Pirdehghan A, Poor Rezaee M, Mirzababaee B. Epidemiology of substance abuse among Iranian adolescents (Yazd: 2014). Iran J Psychiatry Behav Sci. 2017; In Press. [DOI:10.5812/ijpbs.3743]

[18] Mohammadpoorasl A, Nedjat S, Fakhari A, Yazdani K, Rahimi Foroushani A, Fotouhi A. Smoking stages in an Iranian adolescent population. Acta Med Iran. 2012; 50(11):746-54. [PMID]

[19] Ahmadi J, Hasani M. Prevalence of substance use among Iranian high school students. Addict Behav. 2003; 28(2):375-9. [DOI:10.1016/S0306-4603(01)00246-5]

[20] Nazarzadeh M, Bidel Z, Ayubi E, Bahrami A, Jafari F, Mohammadpoorasl $A$, et al. Smoking status in Iranian male adolescents: A cross-sectional study and a meta-analysis. Addict Behav. 2013 38(6):2214-8. [DOI:10.1016/j.addbeh.2013.01.018] [PMID]

[21] Haghdoost AA, Moosazadeh M. The prevalence of cigarette smoking among students of Iran's universities: A systematic review and meta-analysis. J Res Med Sci. 2013; 18(8):717-25. [PMID] [PMCID]

[22] Courtois R, El-Hage W, Moussiessi T, Mullet E. Prevalence of alcohol, drug use and psychoactive substance consumption in samples of French and Congolese high school students. Trop Doct. 2004; 34(1):15-7. [DOI:10.1177/004947550403400106] [PMID] 